\title{
Treatment of knee osteoarthritis with acupuncture combined with Chinese herbal medicine: a systematic review and meta-analysis
}

\author{
Fan Yang, Ying Chen, Zhihui Lu, Wanyi Xie, Shan Yan, Jiao Yang, Yunhai Li \\ Clinical College of Traditional Chinese Medicine, Hubei University of Chinese Medicine, Wuhan, China \\ Contributions: (I) Conception and design: F Yang, Y Li; (II) Administrative support: Y Li; (III) Provision of study materials or patients: F Yang, Y \\ Chen, Z Lu; (IV) Collection and assembly of data: F Yang, W Xie, S Yan; (V) Data analysis and interpretation: F Yang, J Yang; (VI) Manuscript \\ writing: All authors; (VII) Final approval of manuscript: All authors. \\ Correspondence to: Fan Yang; Yunhai Li. Clinical College of Traditional Chinese Medicine, Hubei University of Chinese Medicine, Wuhan 430061, \\ China. Email: 875350152@qq.com; 155350975@qq.com.
}

Backgroundk Many studies have demonstrated that acupuncture combined with Chinese herbal medicine (CHM) effectively treats knee osteoarthritis (KOA), with few side effects. However, few systematic reviews have offered evidence-based support. Here we conducted a meta-analysis on the combination of acupuncture with CHM in treating KOA.

Methods: Databases including CNKI, Wanfang, VIP, PubMed, EMBASE, and Cochrane library were systematically searched for articles on the treatment of KOA by acupuncture combined with CHM from the establishment of the database to May 2021. Three researchers independently searched, screened, extracted, and included articles that met the inclusion standards. The primary outcome measure was overall response rate (ORR), and the secondary outcome measures included Visual Analogue Scale (VAS) score, Western Ontario and McMaster Universities Osteoarthritis Index (WOMAC) score, and Lysholm score. ORR was a binary variable, while other indicators were continuous variables. The quality of literature was assessed with a modified Jadad scale. The RevMan 5.3 software provided by the Cochrane Collaboration was used for statistical analysis.

Results: Thirty-three randomized controlled trials involving 3,954 patients were included. Meta-analysis showed that $\mathrm{ORR}$ [odds ratio $(\mathrm{OR})=5.41 ; 95 \%$ confidence interval $(\mathrm{CI}):(4.38,6.68) ; \mathrm{P}<0.00001$ ], VAS score [mean difference $(\mathrm{MD})=-1.86 ; 95 \% \mathrm{CI}:(-2.44,-1.29) ; \mathrm{P}<0.00001]$, WOMAC score $[\mathrm{MD}=-13.05 ; 95 \%$ CI: $(-21.70,-4.41) ; \mathrm{P}=0.003]$, and Lysholm score [MD $=10.47 ; 95 \% \mathrm{CI}:(5.21,15.72) ; \mathrm{P}<0.0001]$ in the combination group were significantly superior to those in the control group.

Discussion: Compared with acupuncture alone or CHM/Western drug alone, acupuncture combined with CHM can effectively alleviate knee pain, improve knee function, and increase the quality of life. Thus, this combination can be used as a conservative treatment for KOA. However, due to the small number of highquality articles and possible biases in our analysis, our conclusions need to be further verified in more and higher-quality studies.

Keywords: Knee osteoarthritis (KOA); acupuncture; traditional Chinese medicine; randomized controlled trial; meta-analysis

Submitted Aug 04, 2021. Accepted for publication Oct 19, 2021.

doi: 10.21037/apm-21-2565

View this article at: https://dx.doi.org/10.21037/apm-21-2565 


\section{Introduction}

Osteoarthritis $(\mathrm{OA})$ is a chronic degenerative disease that affects approximately $10 \%$ of men and $18 \%$ of women worldwide. The incidence of $\mathrm{OA}$ is increasing annually, along with increased aging. About $60-65 \%$ of people over 60 years of age suffer from symptomatic OA, of which $80 \%$ of patients present with symptoms including joint stiffness and limited range of motion, which seriously affects the quality of life of the victims $(1,2)$. Even worse, an increasing proportion of young adults have also suffered from OA. $\mathrm{OA}$ is a heterogeneous disease caused by multiple factors and characterized by progressive decomposition of articular cartilage. It is commonly believed that knee osteoarthritis (KOA) results from a result of multiple pathogenic factors, such as age, sex, body quality, trauma and genetics, abnormal mechanical load, insufficient nutrition supply and genetic inducement, as well as metabolic factors and infrapatellar fat pad. and is characterized by joint pain and dysfunction with progressive intraarticular and subchondral bone injury, synovitis, osteophyte formation and reduced joint cava. As the prevalence of $\mathrm{OA}$ is rising, the treatment requirements on this disease also increase (3).

The current treatments of KOA mainly include nonsteroidal anti-inflammatory drugs (NSAIDs), chondroitin, hyaluronic acid, surgical therapy, traditional Chinese medicine, acupuncture/massage, and exercise therapy. Weight reduction and muscle strength training around the knee joint may also help. Among them, the combination of acupuncture with Chinese herbal medicine (CHM) is highly effective, with few side effects. Also, it is simple and affordable $(4,5)$.

A previous meta-analysis had investigated the efficacy and safety of this strategy, but with low literature quality, small sample size, and a limited number of response assessment indicators (6). As more relevant articles have been published in recent years, an updated meta-analysis with high-quality articles is warranted to provide accurate, reliable, and multifaceted evidence to evaluate the clinical efficacy of the combination in treating KOA. We present the following article in accordance with the PRISMA reporting checklist (available at https://dx.doi.org/10.21037/apm-21-2565).

\section{Methods}

\section{Literature search strategy}

\section{Computer-based search}

A computer-based search was performed by three researchers.

\section{Databases}

The Chinese databases included CNKI, Wanfang, VIP, and China Biomedical Literature (CBM) database; and English databases included PubMed, EMBASE, and Cochrane Library.

\section{Search words}

The search words included, "acupuncture", "electroacupuncture", "traditional Chinese medicine treatment", "knee osteoarthritis", "osteoarthritis of the knee", "knee joint osteoarthritis", and "KOA", in Chinese and English, respectively.

\section{Time period}

The period between searches was from the month the databases were created to May 2021.

\section{Search strategy}

The search method of combining subject terms with free-text synonyms was used. An example of searching in PubMed is shown in Table 1.

\section{Inclusion and exclusion criteria}

\section{Inclusion criteria}

The inclusion criteria included: (I) the included patients met the diagnostic criteria of KOA; (II) published randomized controlled trials, with clearly-defined baseline data; (III) whether blinding is used or not; (IV) the combination group included patients who had received the combination of acupuncture with CHM alone, while the control group included patients who had undergone other treatment methods different from the combination of acupuncture and CHM; (V) the outcome measures included any of the following indicators: overall response rate (ORR), Visual Analogue Scale (VAS) score, Western Ontario and McMaster Universities Osteoarthritis Index (WOMAC) score, and Lysholm score. All the outcomes measures were reliable.

\section{Exclusion criteria}

The exclusion criteria included: (I) articles with poorlydefined diagnostic criteria, efficacy indicators, and/or descriptions; (II) articles with incorrect trial design or statistical methods; (III) reviews, dissertations, conference proceedings, and nursing records; (IV) basic experiments; (V) case reports and anecdotal evidence; (VI) expert experience; (VII) unpublished articles or overlapping publications; (VIII) 
Table 1 The search strategy for PubMed

\begin{tabular}{lll}
\hline No. & Search term & Search scope \\
\hline$\# 1$ & Acupuncture & [Title/Abstract] \\
$\# 2$ & Electroacupuncture & [Title/Abstract] \\
$\# 3$ & Traditional Chinese medicine & [Title/Abstract] \\
& treatment & \\
$\# 4$ & \#1 OR \#2 OR \#3 & \\
$\# 5$ & Knee osteoarthritis & [Title/Abstract] \\
$\# 6$ & Osteoarthritis of the knee & [Title/Abstract] \\
$\# 7$ & Knee joint osteoarthritis & [Title/Abstract] \\
$\# 8$ & KOA & [Title/Abstract] \\
$\# 9$ & $\# 5$ OR \#6 OR \#7 OR \#8 & \\
$\# 10$ & $\# 4$ AND \#9 & \\
\hline
\end{tabular}

articles with obvious errors or incomplete data; (IX) the original full-text is not available; and (X) literature where acupuncture and CHM are used as adjuvant therapy.

\section{Data extraction}

The search, inclusion, and exclusion of the literature were performed by two well-trained and qualified medical practitioners who had clinical experience in rheumatology and acupuncture, and the initial articles were screened after verification. The data extraction of the initial articles was then performed independently by two investigators and checked by a third investigator. In case of disagreement, the third investigator and the principal investigator negotiated to make a final decision. If there were missing data in the literature, the corresponding author was contacted via email or phone call to obtain such data. The extracted data mainly included: (I) basic information about the included articles: first author and year of publication, etc.; (II) information about the included subjects: number and ages of subjects in the combination group and the control groups, etc.; (III) study designs: types of design, interventions, and details, etc.; and (IV) outcome indicators and outcome measures: ORR, WOMAC score, VAS score, and Lysholm knee function score, etc.

\section{Assessment of literature quality}

The bias risk of the included studies was assessed using the Cochrane Bias Risk tool from the Handbook of the
Cochrane Collaboration for Systematic Intervention Reviews, version 5.1.0 (https://www.cochrane.org/), which assesses the following seven domains: (I) allocation of the randomization sequence (selection bias); (II) allocation concealment (selection bias); (III) blinding of the participants and the team involved (performance bias); (IV) blinding of outcome evaluators (detection bias); (V) incomplete outcomes (attrition bias); (VI) report of selective outcome (publication bias); and (VII) other sources of bias.

The methodological quality of the literature was evaluated according to the Jadad score by two independent researchers with a valid Good Clinical Practice (GCP) certificate, and checked by a third investigator. In case of disagreement, the third investigator and the principal investigator negotiated to make a final decision. Points were awarded as follows: (I) randomization: 1 point was given if randomization was mentioned; additional 1 point was given if appropriate randomization was used; (II) double blinding: 1 point was given if double blinding was mentioned; additional 1 point was given if the method of double blinding was appropriate; and (III) withdrawals and dropouts: 1 point was given for a clear description of withdrawals and dropouts. Articles were rated as low-quality if scored $0-2$ points, and as high-quality if scored 3-5 points.

\section{Outcome measures}

The primary outcome measure was ORR, and the secondary outcome measures included VAS score, WOMAC score, and Lysholm score.

\section{Statistical analysis}

Meta-analysis was performed using RevMan software (version 5.3; Cochrane Collaboration). Both fixedand random-effects models were used. Heterogeneity was quantified by $\mathrm{I}^{2}$ statistics. $\mathrm{I}^{2}<50 \%$ suggested no heterogeneity, and the data were pooled using the fixed-effects model; $\mathrm{I}^{2}>50 \%$ suggested the presence of heterogeneity among the studies, and the random-effects meta-analysis was employed. If more than 10 studies were included for a specific outcome measure, the presence of morbidity bias was analyzed using inverted funnel plots. The odds ratio (OR) was used as the effect measure for binary variables, and the mean difference (MD) was used for measures with the same unit and measurement method. A 95\% confidence interval (CI) was given, and a $\mathrm{P}$ value of $<0.05$ was considered statistically significant. 
Identification of studies via databases and registers

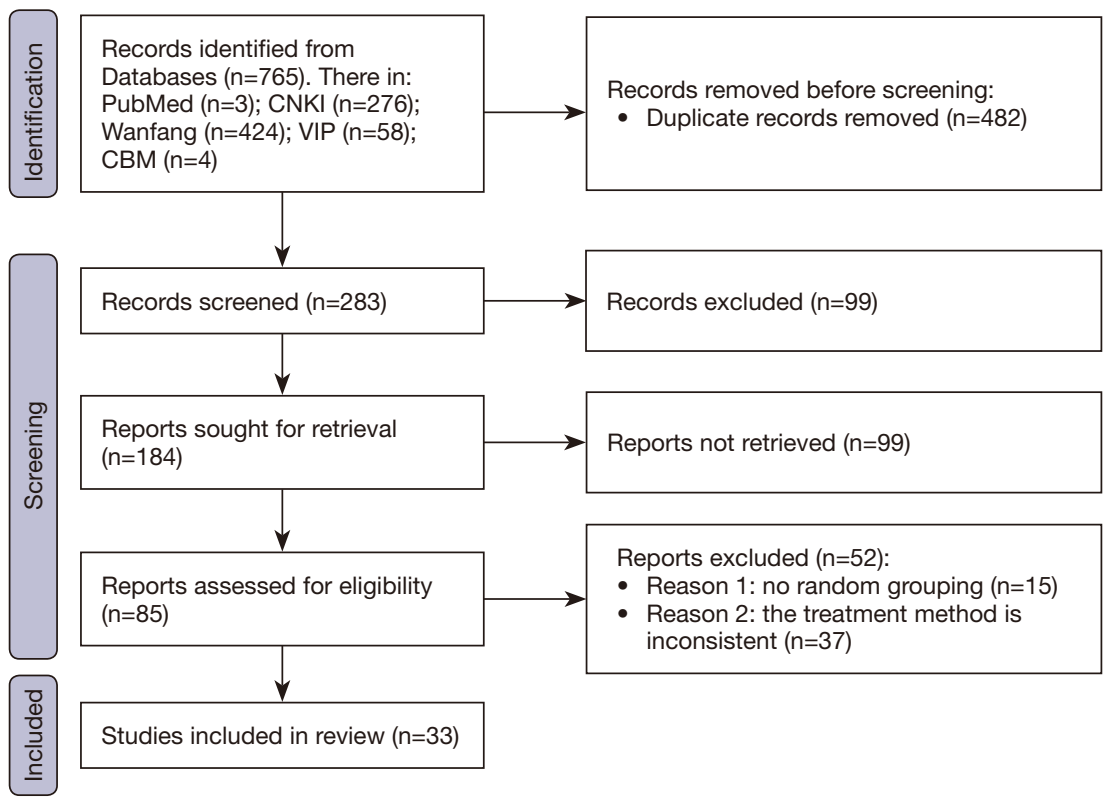

Figure 1 Literature search \& screening flowchart.

\section{Results}

\section{Literature search and screening}

A flow chart of the study selection process is shown in Figure 1.

\section{Basic features of the included studies}

The basic features of the included 33 studies are summarized in Table 2. There is no English literature.

\section{Quality of the included articles}

The included articles' biases were assessed using the relevant tools in the Cochrane Handbook for Systematic Reviews of Interventions. A bar graph showing the assessment results is shown in Figure 2, and a pooled graph is shown in Figure 3.

\section{Outcome measures}

\section{ORR}

ORR was calculated in 31 articles (Figure 4 ). The heterogeneity among studies was low $\left(\mathrm{P}=0.03 ; \mathrm{I}^{2}=36 \%\right)$, so the fixed-effects model was used $[\mathrm{OR}=5.41$ and its $95 \%$
CI was (4.38, 6.68); $\mathrm{Z}=15.66 ; \mathrm{P}<0.00001]$. Meta-analysis showed that the combination group had a higher ORR than the control group. In particular, acupuncture combined with orally administered CHM had significantly higher clinical efficacy compared with other treatment methods. The funnel plot is shown in Figure 5. The plot shows only slight asymmetry, indicating a possible minor publication bias.

\section{VAS score after treatment}

VAS score was mentioned in 3 articles (Figure 6). The heterogeneity among studies was high $(\mathrm{P}<0.00001$; $\left.\mathrm{I}^{2}=98 \%\right)$, so the random-effects model was used [MD $=-1.86$ and its $95 \%$ CI was $(-2.44,-1.29) ; Z=6.37$; $\mathrm{P}<0.00001]$. Meta-analysis showed that the combination group had a larger decrease in VAS score after treatment than the control group. In particular, acupuncture combined with orally administered CHM had significantly higher VAS score improvement than other treatment methods. Thus, the combination could dramatically alleviate the pain symptoms.

\section{WOMAC score after treatment}

WOMAC score was mentioned in 3 articles (Figure 7). The heterogeneity among studies was high $(\mathrm{P}<0.00001$; 
Table 2 Information of the included studies

\begin{tabular}{|c|c|c|c|c|c|c|c|c|}
\hline Articles & Group & $\begin{array}{l}\text { Pooled } \\
\text { sample } \\
\text { size }(n)\end{array}$ & $\begin{array}{c}\text { Gender } \\
\text { (male/female) }\end{array}$ & $\begin{array}{c}\text { Age } \\
\text { (years) }\end{array}$ & $\begin{array}{l}\text { Disease course } \\
\text { (years) }\end{array}$ & Interventions & $\begin{array}{l}\text { Treatment } \\
\text { course }\end{array}$ & $\begin{array}{c}\text { Response } \\
\text { evaluation } \\
\text { criteria }\end{array}$ \\
\hline $\begin{array}{l}\text { Mo LL, } \\
2013 \text { (7) }\end{array}$ & Control group & 320 & $160(76 / 84)$ & $71.50 \pm 3.25$ & $4.60 \pm 2.60$ & Acupuncture & 2 months & $\begin{array}{l}\text { VAS score, LKSS } \\
\text { score, Lysholm } \\
\text { score, response } \\
\text { rate }\end{array}$ \\
\hline 2017 (8) & Control group & & $40(12 / 28)$ & $52 \pm 9$ & 2.4 & $\mathrm{CHM}$ & 4 weeks & ORR \\
\hline \multirow{2}{*}{$\begin{array}{l}\text { Guo PF, } \\
2010(9)\end{array}$} & Combination group & 93 & $55(16 / 39)$ & $38-65$ & 15 days -11 years & Acupuncture $+\mathrm{CHM}$ & \multirow[t]{2}{*}{25 days } & \multirow[t]{2}{*}{ ORR } \\
\hline & Control group & & $38(12 / 26)$ & $40-68$ & 16 days -14 years & Indomethacin & & \\
\hline $\begin{array}{l}\text { Li HT, } \\
2020 \text { (11) }\end{array}$ & Control group & & $40(15 / 25)$ & $53 \pm 7$ & $7.69 \pm 2.01$ & $\mathrm{CHM}$ & 8 weeks & $\begin{array}{l}\text { ORR, WOMAC } \\
\text { score, and VAS } \\
\text { score }\end{array}$ \\
\hline \multirow{2}{*}{$\begin{array}{l}\text { Sun J, } \\
2014 \text { (12) }\end{array}$} & Combination group & 60 & 30 & 56.85 & 23.7 months & Acupuncture $+\mathrm{CHM}$ & \multirow[t]{2}{*}{4 weeks } & \multirow{2}{*}{$\begin{array}{c}\text { Recovery of joint } \\
\text { function and } \\
\text { WOMAC } \\
\text { score }\end{array}$} \\
\hline & Control group & $(16 / 44)$ & 30 & & & Acupuncture & & \\
\hline \multirow{2}{*}{$\begin{array}{l}\text { Zhang H, } \\
2015 \text { (13) }\end{array}$} & Combination group & 200 & $100(41 / 59)$ & $58.58 \pm 10.57$ & - & Acupuncture + $\mathrm{CHM}$ & \multirow[t]{2}{*}{10 days } & \multirow[t]{2}{*}{ ORR } \\
\hline & Control group & & $100(39 / 61)$ & $59.21 \pm 10.54$ & & $\mathrm{CHM}$ & & \\
\hline $\begin{array}{l}\text { Ma X, } \\
2009(14)\end{array}$ & Combination group & 140 & $70(-/-)$ & - & - & $\begin{array}{l}\mathrm{CHM}+\text { acupuncture } \\
+ \text { topical washing + } \\
\text { ultrashort wave therapy } \\
+ \text { computerized } \\
\text { medium frequency } \\
\text { therapy + direct current } \\
\text { induction therapy }\end{array}$ & $\begin{array}{l}15 \text { days } \\
\text { y } \\
\text { it }\end{array}$ & ORR \\
\hline \multirow[t]{2}{*}{$\begin{array}{l}\text { Feng Z, } \\
2014 \text { (15) }\end{array}$} & Combination group & 100 & $50(22 / 28)$ & $56 \pm 9.8$ & - & $\begin{array}{l}\mathrm{CHM}+\text { acupuncture + } \\
\text { topical application }\end{array}$ & \multirow[t]{2}{*}{14 days } & \multirow[t]{2}{*}{ ORR and HSS } \\
\hline & Control group & & $50(19 / 31)$ & $54 \pm 10.1$ & & $\mathrm{CHM}$ & & \\
\hline \multirow[t]{2}{*}{$\begin{array}{l}\text { Liu XM, } \\
2016(16)\end{array}$} & Combination group & $\begin{array}{c}80 \\
(42 / 38)\end{array}$ & 40 & $55 \pm 6.7$ & $1.2 \pm 0.5$ & $\begin{array}{l}\mathrm{CHM}+\text { acupuncture }+ \\
\text { massage }\end{array}$ & 3 weeks & \multirow[t]{2}{*}{ ORR } \\
\hline & Control group & & 40 & & & Nobumetone capsules & 6 weeks & \\
\hline \multirow{2}{*}{$\begin{array}{l}\text { Gui HQ, } \\
2019(17)\end{array}$} & Combination group & 100 & $50(32 / 18)$ & $53.89 \pm 2.56$ & $4.01 \pm 0.45$ & Acupuncture + CHM & \multirow[t]{2}{*}{10 days } & \multirow{2}{*}{$\begin{array}{c}\text { ORR, } \\
\text { functional } \\
\text { improvement } \\
\text { time, inflammatory } \\
\text { factors, and joint } \\
\text { function score }\end{array}$} \\
\hline & Control group & & $50(31 / 19)$ & $53.25 \pm 2.24$ & $4.03 \pm 0.42$ & $\mathrm{CHM}$ & & \\
\hline
\end{tabular}

Table 2 (continued) 
Table 2 (continued)

\begin{tabular}{|c|c|c|c|c|c|c|c|c|}
\hline Articles & Group & $\begin{array}{l}\text { Pooled } \\
\text { sample } \\
\text { size }(n)\end{array}$ & $\begin{array}{c}\text { Gender } \\
\text { (male/female) }\end{array}$ & Age (years) & $\begin{array}{l}\text { Disease course } \\
\text { (years) }\end{array}$ & Interventions & $\begin{array}{c}\text { Treatment } \\
\text { course }\end{array}$ & $\begin{array}{c}\text { Response } \\
\text { evaluation } \\
\text { criteria }\end{array}$ \\
\hline $\begin{array}{l}\text { Ma YH, } \\
2017 \text { (18) }\end{array}$ & Control group & $\begin{array}{c}81 \\
(30 / 51)\end{array}$ & 36 & $52-69$ & - & $\mathrm{CHM}$ & 28 days & ORR \\
\hline $\begin{array}{l}\text { Chen LS, } \\
2017 \text { (19) }\end{array}$ & Combination group & 168 & $84(35 / 49)$ & 54.2 & 7.3 & Acupuncture $+\mathrm{CHM}$ & 5 weeks & ORR \\
\hline \multirow[t]{2}{*}{$\begin{array}{l}\text { Ma P, } \\
2011(21)\end{array}$} & Combination group & 166 & $83(42 / 41)$ & 51.2 & 7.5 months & $\begin{array}{l}\mathrm{CHM}+\text { acupuncture }+ \\
\text { ibuprofen extended } \\
\text {-release capsules }\end{array}$ & \multirow[t]{2}{*}{30 days } & \multirow[t]{2}{*}{ ORR } \\
\hline & Control group & & $83(44 / 39)$ & 52.5 & 7.2 months & $\begin{array}{l}\text { Ibuprofen extended } \\
\text {-release capsules }\end{array}$ & & \\
\hline $\begin{array}{l}\text { Ge XT, } \\
2009 \text { (22) }\end{array}$ & Combination group & 200 & $150(49 / 101)$ & $\begin{array}{c}55.8 \\
(39 / 85)\end{array}$ & 30 days -12 years & $\begin{array}{l}\text { CHM + acupuncture } \\
+ \text { medium-frequency } \\
\text { electrotherapy }\end{array}$ & 60 days & ORR \\
\hline $\begin{array}{l}\text { Sun ZJ, } \\
2013(23)\end{array}$ & Control group & & 140 & & & Nobumetone capsules & 3 weeks & $\begin{array}{l}\text { ORR and pain scale } \\
\text { scores }\end{array}$ \\
\hline \multirow[t]{2}{*}{$\begin{array}{l}\text { Zhu LY, } \\
2020 \text { (24) }\end{array}$} & Combination group & 60 & $30(15 / 15)$ & $61.50 \pm 6.85$ & $1.29 \pm 0.26$ & $\begin{array}{l}\mathrm{CHM}+\text { acupuncture/ } \\
\text { massage + meloxicam } \\
\text { + sodium hyaluronate }\end{array}$ & 4 weeks & \multirow[t]{2}{*}{$\begin{array}{c}\text { ORR and Lysholm } \\
\text { score }\end{array}$} \\
\hline & Control group & & $30(14 / 16)$ & $62.11 \pm 7.11$ & $1.34 \pm 0.25$ & $\begin{array}{l}\text { Oral meloxicam } \\
\text { capsule + intra-articular } \\
\text { injection of sodium } \\
\text { hyaluronate }\end{array}$ & & \\
\hline \multirow[t]{2}{*}{$\begin{array}{l}\text { Wang RJ, } \\
2019 \text { (25) }\end{array}$} & Combination group & 100 & $50(30 / 20)$ & $49.7 \pm 5.2$ & $8.3 \pm 4.3$ & $\begin{array}{l}\mathrm{CHM}+\text { acupuncture } \\
+ \text { sparrow-pecking } \\
\text { moxibustion }\end{array}$ & - & \multirow{2}{*}{$\begin{array}{l}\text { ORR, degree of } \\
\text { knee joint motion, } \\
\text { and knee pain } \\
\text { score }\end{array}$} \\
\hline & Control group & & $50(27 / 23)$ & $50.8 \pm 6.2$ & $9.3 \pm 3.3$ & $\mathrm{CHM}$ & & \\
\hline
\end{tabular}

Table 2 (continued) 
Table 2 (continued)

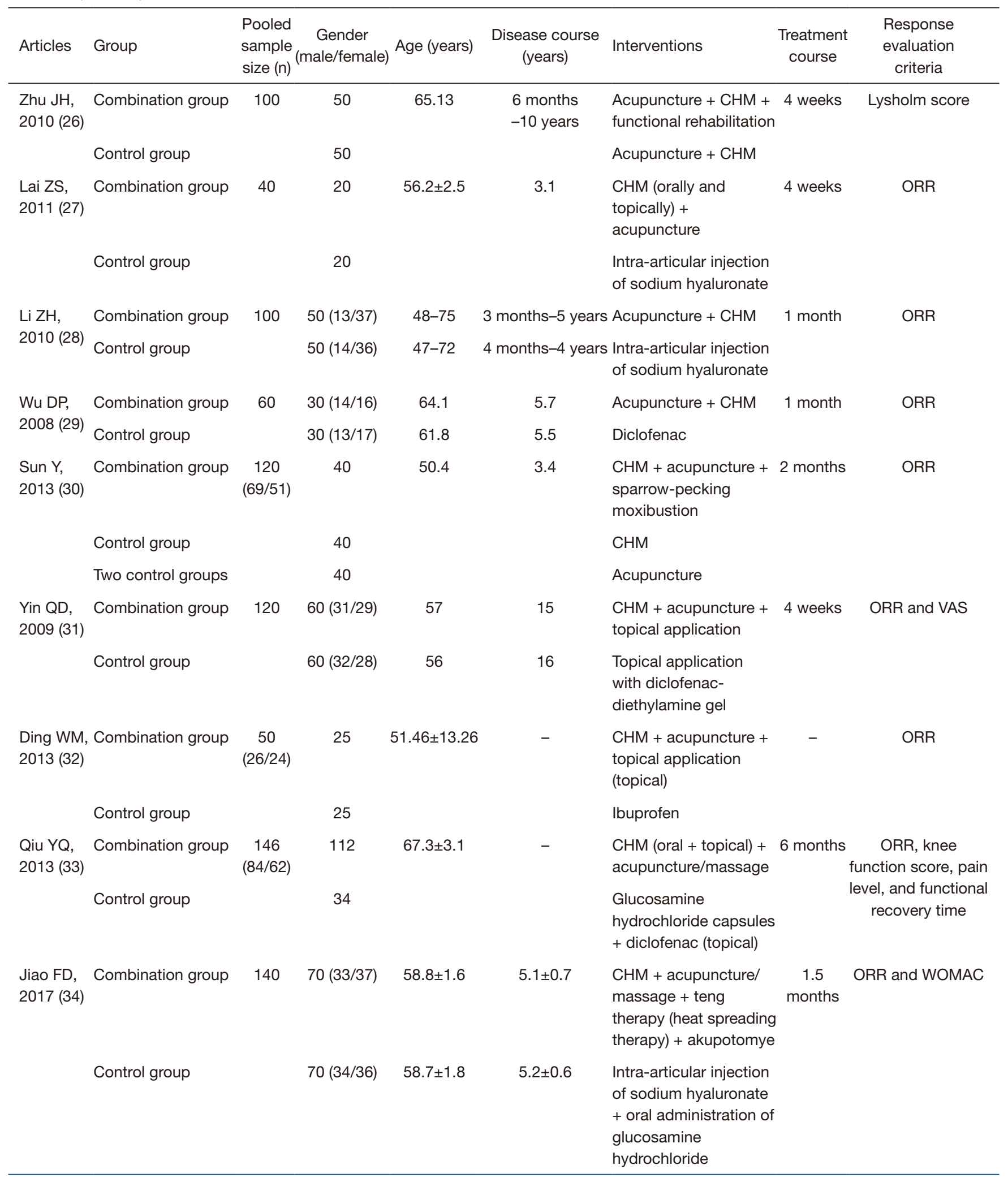

Table 2 (continued) 
Table 2 (continued)

\begin{tabular}{|c|c|c|c|c|c|c|c|c|}
\hline Articles & Group & $\begin{array}{l}\text { Pooled } \\
\text { sample } \\
\text { size }(n)\end{array}$ & $\begin{array}{c}\text { Gender } \\
\text { (male/female) }\end{array}$ & Age (years) & $\begin{array}{l}\text { Disease course } \\
\text { (years) }\end{array}$ & Interventions & $\begin{array}{l}\text { Treatment } \\
\text { course }\end{array}$ & $\begin{array}{l}\text { Response } \\
\text { evaluation } \\
\text { criteria }\end{array}$ \\
\hline $\begin{array}{l}\text { Huang } \\
X W, 2018 \\
(35)\end{array}$ & Control group & & $40(14 / 24)$ & $58.1 \pm 7.62$ & & $\begin{array}{l}\text { Acupuncture + } \\
\text { massage }\end{array}$ & & $\begin{array}{l}\text { sensation score, } \\
\text { joint swelling score, } \\
\text { and arthritis index }\end{array}$ \\
\hline \multirow[t]{2}{*}{$\begin{array}{l}\text { Bai Y, } \\
2017(36)\end{array}$} & Combination group & 104 & $52(27 / 25)$ & $63.2 \pm 5.1$ & $7.1 \pm 3.2$ & $\begin{array}{l}\text { Intra-articular injection } \\
\text { of sodium hyaluronate } \\
+\mathrm{CHM}+\text { acupuncture }\end{array}$ & 1 month & ORR \\
\hline & Control group & & $52(23 / 29)$ & $65.5 \pm 4.7$ & $6.3 \pm 3.1$ & Sodium hyaluronate & & \\
\hline $\begin{array}{l}\text { Yu ZX, } \\
2017 \text { (37) }\end{array}$ & Combination group & 112 & $56(30 / 26)$ & $59.7 \pm 7.2$ & $22.7 \pm 11.9$ & $\begin{array}{l}\mathrm{CHM}+\text { acupuncture }+ \\
\text { massage }\end{array}$ & - & ORR \\
\hline $\begin{array}{l}\text { Chen SY, } \\
2015(38)\end{array}$ & Combination group & 210 & $120(74 / 46)$ & 62 & 9.8 & $\begin{array}{l}\text { CHM decoctions, } \\
\text { fumigation and soaking } \\
\text { therapy, massage, } \\
\text { small akupotomye, } \\
\text { acupuncture, } \\
\text { symptomatic pain } \\
\text { relief, and intra- } \\
\text { articular } \\
\text { injection of sodium } \\
\text { hyaluronate }\end{array}$ & y & ORR \\
\hline
\end{tabular}

CHM, Chinese herbal medicine; NSAID, non-steroidal anti-inflammatory drugs; VAS, Visual Analogue Scale; LKSS, Lysholm knee score; ORR, overall response rate; WOMAC, Western Ontario and McMaster Universities Osteoarthritis Index; HSS, hospital for special surgery knee score; ESR, erythrocyte sedimentation rate.

$\left.\mathrm{I}^{2}=100 \%\right)$, so the random-effects model was used $[\mathrm{MD}$ $=-13.05$ and its $95 \%$ CI was $(-21.70,-4.41) ; Z=2.96$; $\mathrm{P}=0.003]$. Meta-analysis showed that the combination group had a larger decrease in WOMAC score after treatment than the control group. In particular, acupuncture combined with orally administered CHM had a significantly higher decrease in WOMAC score compared with other treatment methods. Thus, the combination could effectively relieve knee pain and stiffness in KOA patients and improve their daily living difficulties.

\section{Lysholm score after treatment}

Lysholm score was mentioned in 2 articles (Figure 8). The heterogeneity among studies was high $\left(\mathrm{P}=0.007 ; \mathrm{I}^{2}=86 \%\right)$, so the random-effects model was used $[\mathrm{MD}=10.47$ and its 95\% CI was (5.21, 15.72); $\mathrm{Z}=3.91 ; \mathrm{P}<0.0001]$. Meta-analysis showed that the combination group had a higher Lysholm score after treatment than the control group. In particular, acupuncture combined with orally administered CHM significantly increased the Lysholm score compared with other treatment methods. Thus, the combination could 


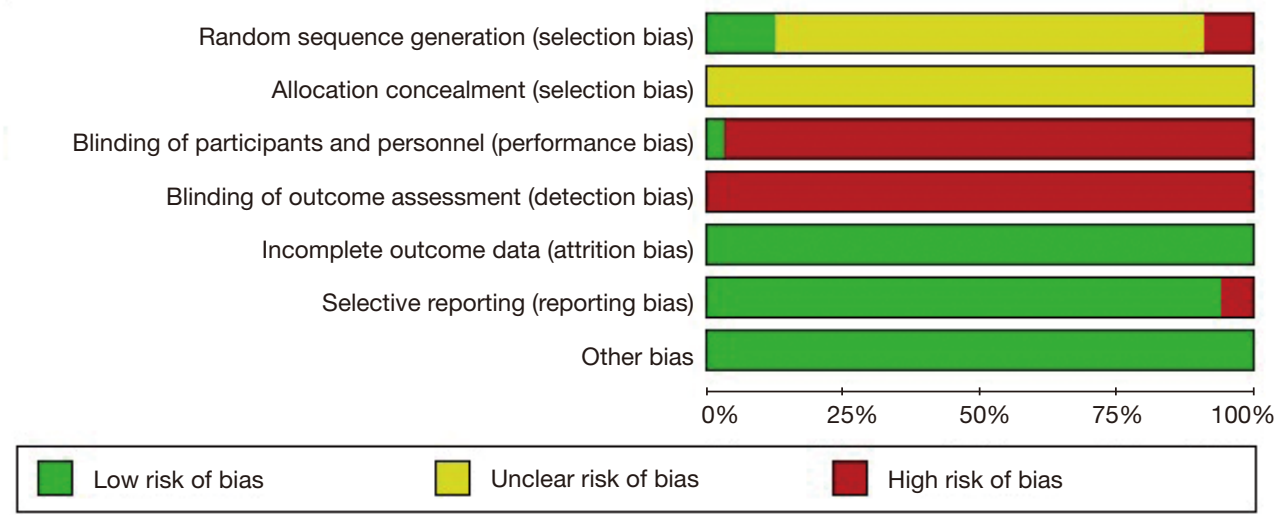

Figure 2 Bar chart for bias risks of the included studies.

effectively relieve knee pain, stiffness, and swelling in KOA patients, and improve the quality of life.

\section{Adverse reactions}

Adverse reactions were mentioned in two studies (Figure 9). In one study, the incidence of adverse reactions was $1.92 \%$ (mild swelling of the lower extremities in one case) and $3.85 \%$ (diarrhea in one case and dizziness in one case), respectively, in the control group and the combination group, showing no significant difference $(\mathrm{P}>0.05)$. In another study, two patients in the combination group experienced mild gastrointestinal discomfort and abdominal distension, which disappeared after stopping the CHM. Three patients showed gastrointestinal reactions in the control group, manifested as nausea, vomiting, abdominal pain, and constipation, which resolved after stopping the CHM. There were no significant changes in the findings of routine blood tests, routine urine tests, and liver/kidney function tests before and after treatment in both groups.

\section{Discussion}

$\mathrm{KOA}$ is a common degenerative disease of the knee joint, with the main symptoms being knee stiffness, pain, and movement disorders. Currently, the commonly used Western medical treatments, including Western drugs or surgery, still cannot cure KOA and are often associated with adverse effects (40). Therefore, the role of TCM in treating KOA has been increasingly recognized, particularly the combination of acupuncture with orally administered CHM. The clinical efficacy of acupuncture has long been demonstrated. When used in combination with liverand kidney-tonifying drugs, wind-, cold-, and dampnessdispelling drugs, and blood circulation-activating drugs, acupuncture can alleviate KOA and reduce its recurrence. It also helps increase the patient's quality of life and improve the economic/psychological burden of patients and their families.

The acupuncture points mentioned in the literature included neixiyan, waixiyan, zusanli, xuehai, liangqiu, yinlingquan, yanglingquan, weizhong, and ashi point, which are around the knee joint. Acupuncture at these points helps alleviate knee pain and regulate qi and blood. Acupuncture can enhance muscle strength, adjust soft tissue tension around the knee, improve joint stress, eliminate swelling and relieve pain. And promote local blood circulation, accelerate metabolism, benefit the absorption of inflammatory substances in the joint, enable the damaged tissue to repair, relieve the resting pain of the knee joint, swelling, pain from up and down stairs, stiffness and the improvement of joint mobility. The TCM orally administered Radix Angelicae Pubescentis, parasite scurrula, Radix Cyathulae, Poria, Radix Saposhnikoviae, Rhizoma Ligustici Chuanxiong, Radix Codonopsis, Radix Angelicae Sinensis, Radix Paeoniae Alba, Radix Rehmanniae Preparata, Radix Aconiti Preparata, and Eupolyphaga Seu Steleophaga. They were mainly liverand kidney-tonifying drugs and blood circulation-activating drugs. It has modern pharmacological effects such as anti-inflammatory, analgesia, expanding blood vessels, improving circulation and regulating immune functions. The Chinese herbs with the actions of activating blood flow and removing blood stasis, and strengthening the muscles 


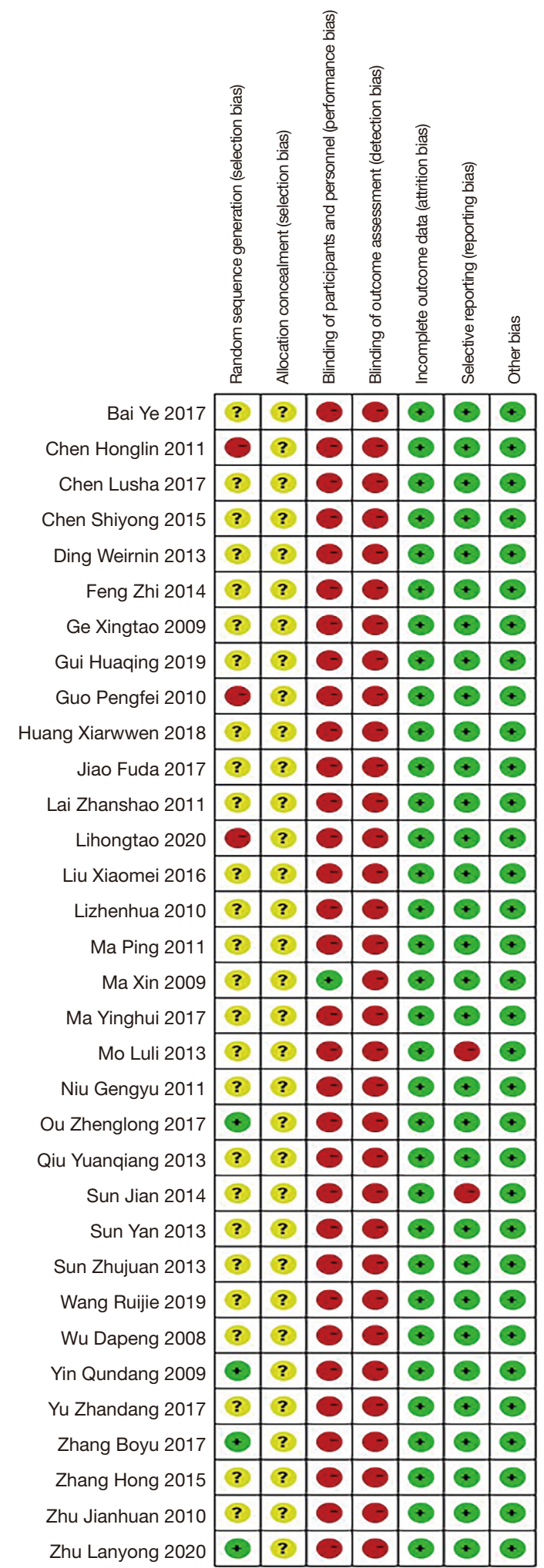

Figure 3 Bias risk assessment of the included studies. +, low risk; ?, unknown; -, high-risk. and bones were applied to the affected sites and irradiation by the spectrograp can promote the local absorption of medicines. Herbs with the effects of activating blood flow and removing blood stasis can ameliorate hemodynamical state, promote the microcirculation and improve the hypercoagulability to relieve blood stasis. Moreover, the herbs effective to nourish the kidney and strengthen effective to bones, activate blood flow and remove blood stasis can inhibit chrondral degeneration and promote the auto-reparation of the cartilagines TCM. Thus, they can exert very well effects in treating and preventing the KOA. The combination treats the disease via both oral and topical approaches, and from local and systemic perspectives. Strengthening the tendons, bones, and joints relieves knee pain and improve the quality of life in KOA patients.

Here we systematically evaluated the efficacy of the combination in treating KOA. A meta-analysis was conducted on the retrieved studies. Data were extracted from studies without significant heterogeneity and pooled with appropriate statistical methods to draw comprehensive conclusions, which to a certain extent can yield more reliable clinical data. The results suggested that the combination could effectively increase the ORR and reduce disease recurrence. However, most of the included articles were of low quality, as they failed to strictly follow the requirements of randomized control trials (e.g., blinding), and some of them were biased. The limitations of our current analysis are summarized as follows: (I) due to insufficient relevant foreign language literature, the included articles were all small-sample, single-center randomized controlled trials published in China, which could lead to selection bias; (II) most of the studies did not mention allocation concealment and blinding, which may have some influence on the results due to the risk of bias; (III) the duration of treatment, follow-up time, and specific acupuncture points/CHM varied among different studies, so there was statistical heterogeneity; (IV) while the vast majority of randomized controlled trials focusing on the combination of acupuncture and $\mathrm{CHM}$ in treating KOA were included in our current analysis, only a few studies on the combinations with warm acupuncture, small needle knife, and Western medicine were retrieved for comparisons, which may result in a certain risk of bias; and (V) the three indicators, including WOMAC score, VAS score, and Lysholm score, were adopted in only a small number of studies used, and were highly heterogeneous among these studies due to differences in treatment course, interventions in control group, and grouping 


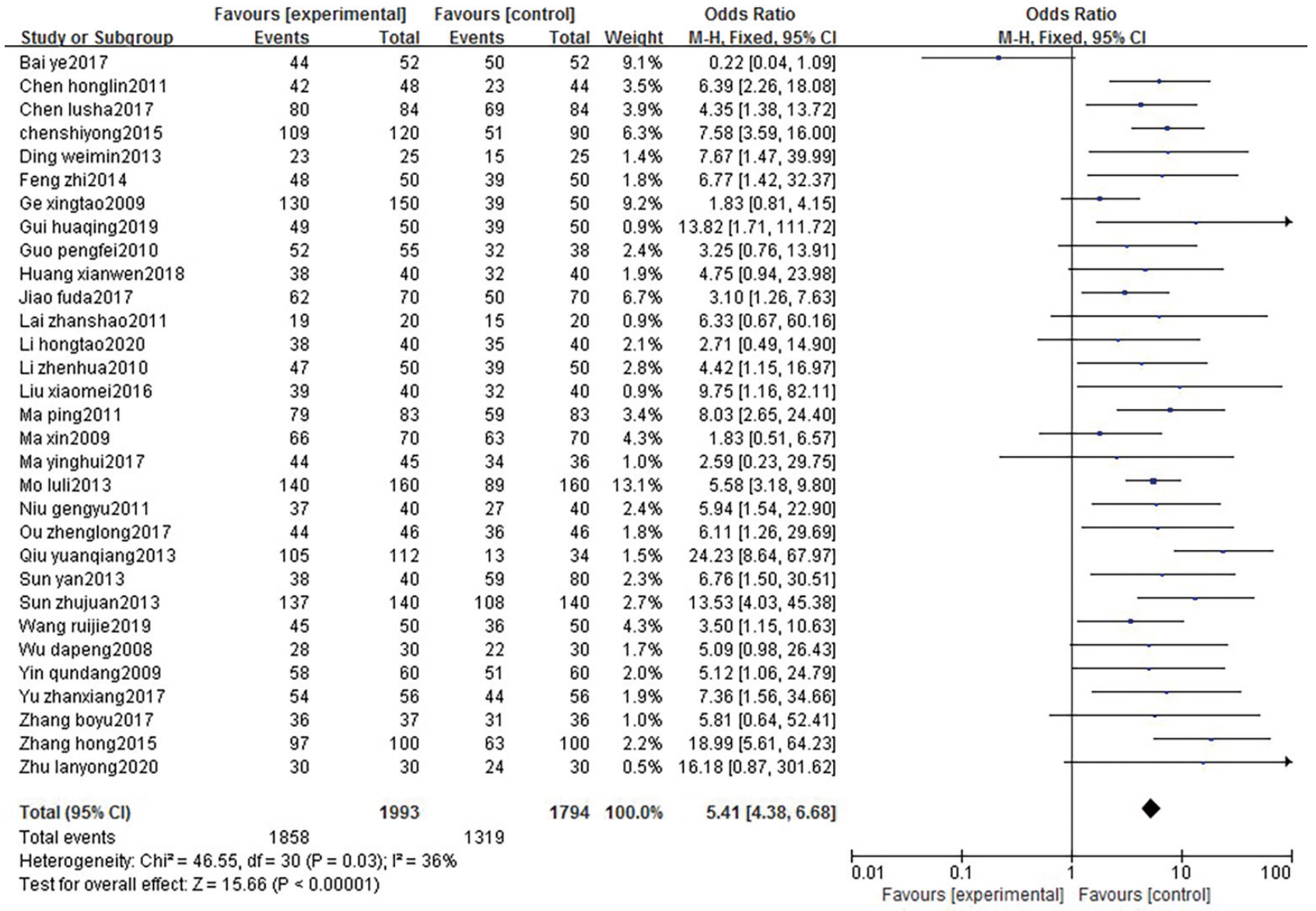

Figure 4 Forest plot of the meta-analysis of ORR. ORR, overall response rate.

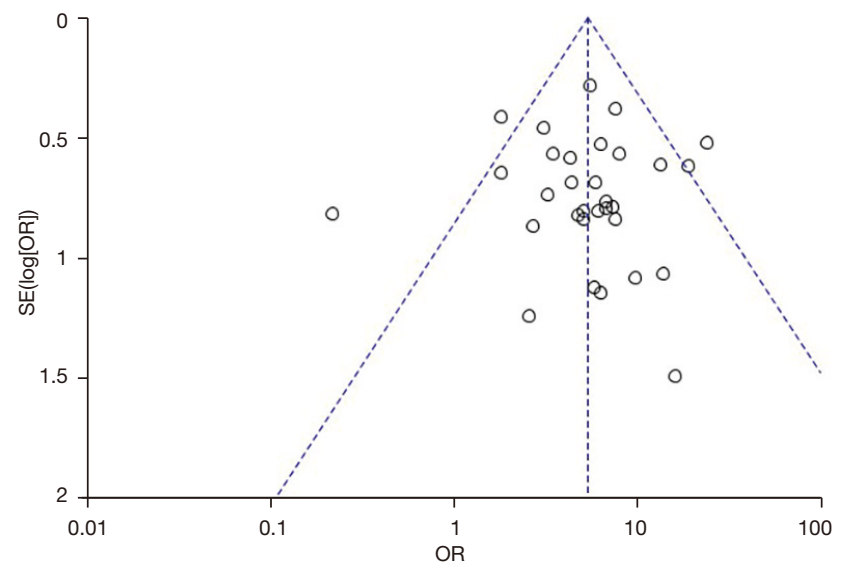

Figure 5 Funnel plot of the meta-analysis of ORR. ORR, overall response rate; OR, odds ratio; $\mathrm{SE}$, standard error.

protocols, which undermined the reliability of the results $(41,42)$.

\section{Limitations and beterogeneity}

The limitations of meta-analysis: 33 studies were included, mostly randomized methods and random assignment, some had only overall efficiency, too-old or self-contained efficacy criteria; most literature lacked long-term follow-up data to evaluate patients' disease recurrence, long-term survival quality and specific adverse effects. Evaluation indicators were limited, the outcome indicators only analyzed efficiency, VAS, WOMAC score and Lysholm joint function score, such as HSS score, Inflammatory factor and adverse events were not included in the analysis. On systematic review, the article has some bias in systematic review, selection bias, incomplete or not objective; in research level, there may be publication bias, positive results are easy to publish, negative results are not acceptable, in outcome level, researchers have reporting bias, Selective reports of favorable results.

The article on the source of heterogeneity to consider 


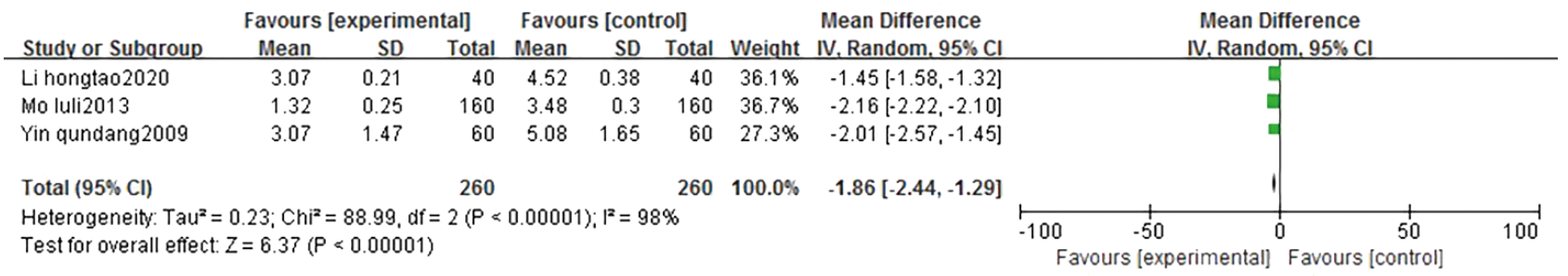

Figure 6 Forest plot of meta-analysis of VAS score after treatment. VAS, Visual Analogue Scale.

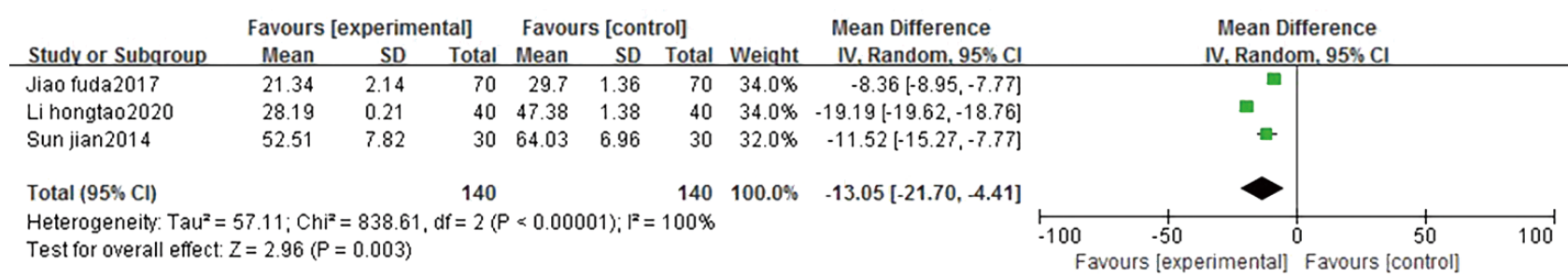

Figure 7 Forest plot of meta-analysis of WOMAC score after treatment. WOMAC, Western Ontario and McMaster Universities Osteoarthritis Index.

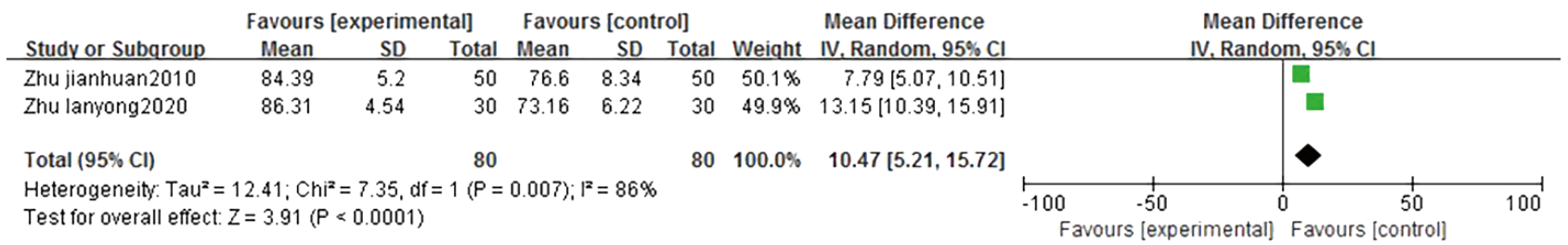

Figure 8 Forest plot of meta-analysis of Lysholm score after treatment.

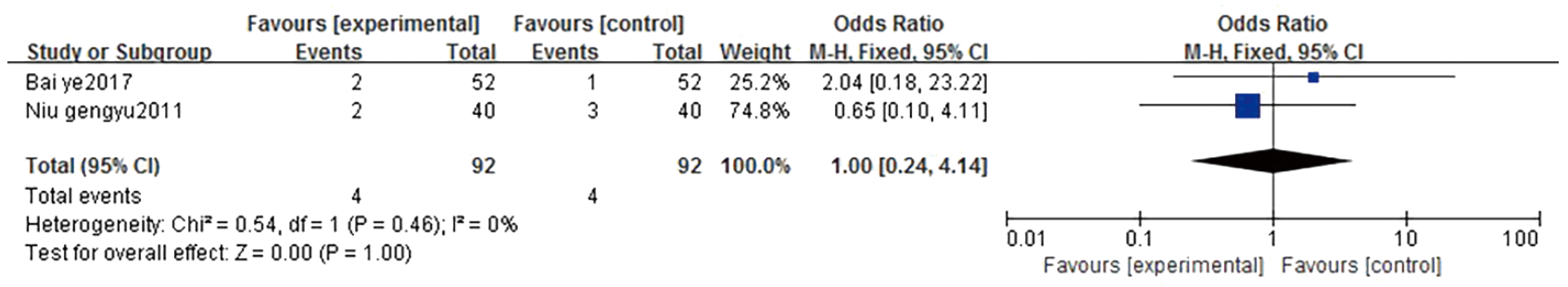

Figure 9 Forest plot of adverse reactions.

the following points: acupuncture selected acupoints are different: far away Near selection points, with the evidence selection points, meridian syndrome differentiation selection points and viscera syndrome differentiation selection points, etc.

The oral CHMs selected in the literature are also different, including tonifying the liver and kidney, strengthening tendons and bones, promoting blood circulation and dredging collaterals, regulating qi and so on, which will also cause some heterogeneity.

In conclusion, the combination of acupuncture with CHM has significant efficacy in treating KOA, with remarkable therapeutic effects in improving ORR, increasing Lysholm score, and lowering VAS score and WOMAC score. With 
a high clinical value, it may be a preferred treatment for KOA. However, as the currently available studies still had many limitations, the conclusions of our analysis still need to be further validated in more multicenter, large-sample randomized controlled trials at home and abroad. Based on our findings, future studies may increase their quality by optimizing research protocols and increasing sample sizes. In addition, the clinical value of the combination of acupuncture with CHM in treating KOA has been demonstrated, and the underlying mechanism may be a research priority (43).

\section{Acknowledgments}

Funding: This study was supported by Hubei University of Chinese Medicine "Youth Program" (2020ZZX029) and Hubei University of Chinese Medicine Doctoral Research Start-Up Fund.

\section{Footnote}

Reporting Checklist: The authors have completed the PRISMA reporting checklist. Available at https://dx.doi. org/10.21037/apm-21-2565

Conflicts of Interest: All authors have completed the ICMJE uniform disclosure form (available at https://dx.doi. org/10.21037/apm-21-2565). The authors have no conflicts of interest to declare.

Ethical Statement: The authors are accountable for all aspects of the work in ensuring that questions related to the accuracy or integrity of any part of the work are appropriately investigated and resolved.

Open Access Statement: This is an Open Access article distributed in accordance with the Creative Commons Attribution-NonCommercial-NoDerivs 4.0 International License (CC BY-NC-ND 4.0), which permits the noncommercial replication and distribution of the article with the strict proviso that no changes or edits are made and the original work is properly cited (including links to both the formal publication through the relevant DOI and the license). See: https://creativecommons.org/licenses/by-nc-nd/4.0/.

\section{References}

1. Sun Q, Zhang K, Chen J, et al. Traditional Chinese medicine classification of knee osteoarthritis with proteomics analysis. Ann Palliat Med 2020;9:3750-6.

2. Xie H, Pan JK, Hong KH, et al. Taijiquan for osteoarthritis: a systematic review and meta-analysis. China Journal of Traditional Chinese Medicine and Pharmacy 2016;31:1863-7.

3. Xu L, Jing $\mathrm{Y}$, Zhao C, et al. Cross-sectional analysis of the association between serum uric acid levels and handgrip strength among Chinese adults over 45 years of age. Ann Transl Med 2020;8:1562.

4. Wang D, Yun J, Li XY, et al. Effectiveness of TCM collapse stain therapy in treating knee osteoarthritis: a meta analysis. Chinese General Practice Nursing 2019;17:780-4.

5. Huang ZL, Shi SN, He JJ, et al. Meta-analysis of safety and effectiveness of proximal fibular osteotomy and high tibial osteotomy in the treatment of knee osteoarthritis. Chinese Journal of Tissue Engineering Research 2021;25:2945-52.

6. Chen LY, Lin ZY, Yin LH, et al. System review and metaanalysis on the combination of acupuncture with medicine in the treatment of knee osteoarthritis. Guangming Journal of Chinese Medicine 2018;33:3047-50.

7. Mo LL, Huang HF, Liu JJ, et al. Observation of kidneynourishing therapy of acupuncture combined with Traditional Chinese medicine therapy on osteoarthritis of knee joint. Hebei Journal of Traditional Chinese Medicine 2013;35:557-9.

8. Zhang BY, Jiang LL. Clinical efficacy of electroacupuncture combined with traditional Chinese medicine in the treatment of early osteoarthritis of the knee. Clinical Laboratory Journal (Electronic Edition) 2017;6:143-5.

9. Guo PF. The efficacy of Duhuo Jisheng decoction with electroacupuncture in 55 cases of osteoarthritis of the knee. Inner Mongol Journal of Traditional Chinese Medicine 2010;29:17, 113.

10. Chen HL, Wu ML, Chen LJ, et al. The efficacy of Duhuo Jisheng decoction with electroacupuncture in treating osteoarthritis of the knee. Journal of Guiyang College of Traditional Chinese Medicine 2011;33:43-4.

11. Li HT, Yang Y, Sun XW. Jingulian Capsule combined with electroacupuncture in treating knee osteoarthritis. Journal of Changchun University of Traditional Chinese Medicine 2020;36:120-2.

12. Sun J, Kong XC, Che T, et al. The efficacy observation of the treatment of Jintiange capsule combined with electroacupuncture for knee osteoarthritis. Chinese Journal of Osteoporosis 2014;20:1443-6. 
13. Zhang H. An investigation of the effect of combined orally and topically administered Chinese herbal medicine and acupuncture therapy in the treatment of osteoarthritis of the knee joint. Contemporary Medicine Forum 2015;13:265-6.

14. Ma X. Comprehensive treatment of knee osteoarthritis in 70 cases. Journal of Practical Traditional Chinese Internal Medicine 2009;23:78-9.

15. Feng Z. Clinical efficacy of combined internal and external treatments for osteoarthritis of the knee. For All Health 2014;8:126.

16. Liu XM. Effectiveness of combined treatment with acupuncture, moxibustion, massage, and traditional Chinese herbal medicine for early knee osteoarthritis. China Health Care \& Nutrition 2016;11:350.

17. Gui HQ. Treatment of osteoarthritis of the knee joint using traditional Chinese herbal medicine plus acupuncture. Healthmust-Readmagazine 2019;3:199.

18. Ma YH, Li Z, Zhai WT, et al. Efficacy of acupuncture combined with traditional Chinese herbal medicine in the treatment of osteoarthritis of the knee. World Latest Medicine Information 2017;17:155-6.

19. Chen LS. Clinical efficacy of acupuncture combined with traditional Chinese herbal medicine in the treatment of knee osteoarthritis. World Latest Medicine Information 2017;17:80.

20. Ou ZL, Zeng XY. Efficacy of acupuncture combined with TCM internal therapy in the treatment of knee osteoarthritis. Journal of Emergency in Traditional Chinese Medicine 2017;26:2020-2.

21. Ma P. 83 cases of knee osteoarthritis treated with acupuncture combined with Shentong Zhuyu decoction. Chinese Medicine Modern Distance Education of China 2011;9:141.

22. Ge XT, Dong LH, Wang JR, et al. 150 cases of knee osteoarthritis treated with acupuncture combined with traditional Chinese herbal medicine. Chinese Journal of Traditional Medical Science and Technology 2009;16:485.

23. Sun ZJ. Effectiveness of acupuncture, massage, and traditional Chinese herbal medicine in the treatment of early knee osteoarthritis. Seek Medical and Ask the Medicine 2013;11:137-8.

24. Zhu LY, Zhang H. Observation on the effect of acupuncture and massage combined with traditional Chinese medicine in the treatment of early knee osteoarthritis. Reflexology and Rehabilitation Medicine 2020;1:44-6.

25. Wang RJ. Effectiveness and mechanism of acupuncture in the treatment of knee osteoarthritis. China Health Care \& Nutrition 2019;29:361.

26. Zhu JH, Sun HJ, Chen WY, et al. Acupuncture and herbs combined with genouillere and functional exercise in treatment for the elder patients with knee osteoarthritis. International Medicine and Health Guidance News 2010;16:2980-2.

27. Lai ZS. Treatment of knee osteoarthritis with acupuncture and Chinese herbal medicine in 40 cases. China Practical Medicine 2011;6:168-9.

28. $\mathrm{Li} \mathrm{ZH}$. Acupuncture and osteoarthritis of the knee governance 50 cases. Journal of Practical Traditional Chinese Internal Medicine 2010;24:83-4.

29. Wu DP, Zhao B. Treatment of knee osteoarthritis with acupuncture and Chinese herbal medicine in 30 cases. China Practical Medicine 2008;3:50-1.

30. Sun Y, Chen LZ, Sun HD, et al. Clinical study of 120 cases of knee osteoarthritis treated with a combination of acupuncture and traditional Chinese herbal medicine. Yiayao Qianyan 2013;(14):207-8.

31. Yin QD. Combination of acupuncture and traditional Chinese herbal medicine in treating knee osteoarthritis. Gansu Journal of Traditional Chinese Medicine 2009;22:22-3.

32. Ding WM. Clinical efficacy of multidisciplinary traditional Chinese medicine-based therapies for knee osteoarthritis. Asia-Pacific Traditional Medicine 2013;9:78.

33. Qiu YQ. Clinical research of traditional Chinese medicine treatment of early osteoarthritis of the knee. China Health Industry 2013;10:10-1.

34. Jiao FD, Wu B. Clinical observation on the treatment of early and middle stage knee osteoarthritis with fourdimensional therapy of traditional Chinese medicine. Journal of Shenyang Medical College 2017;19:316-8.

35. Huang XW, Bao AT. Effectiveness of the combination of traditional Chinese herbal medicine with acupuncture and massage in relieving hyperplastic osteoarthropathy of knee joint. Healthmust-Readmagazine 2018;1:184-5.

36. Bai Y, Liu SH. Efficacy of orally-administered traditional Chinese herbal medicine plus acupuncture combined with injection of sodium hyaluronate in 52 cases of osteoarthritis of knee. Nei Mongol Journal of Traditional Chinese Medicine 2017;36:80-1.

37. Yu ZX, Tang XJ. Combination of traditional Chinese herbal medicine with massage and acupuncture in the treatment of knee osteoarthritis. China Health Care \& Nutrition 2017;(1):316.

38. Chen SY. Combination of Chinese and Western methods 
for the treatment of knee osteoarthritis. Journal of Sichuan Traditional Chinese Medicine 2015;33:129-30.

39. Niu GY. Efficacy of acupuncture combined with the formula of tonifying the kidney and activating blood in the treatment of knee osteoarthritis. China Foreign Medical Treatment 2011;(12):130.

40. Zeng LF, Yang WY, Guo D, et al. System evaluation of traditional exercise therapy intervention on pain and joint function improvement in patients with knee osteoarthritis. China Journal of Traditional Chinese Medicine and Pharmacy 2018;33:2132-9.

41. Yin YH, Zhan JW, Wang SQ, et al. Meta-analysis of acupuncture combined with massage in the treatment of

Cite this article as: Yang F, Chen Y, Lu Z, Xie W, Yan S, Yang J, Li Y. Treatment of knee osteoarthritis with acupuncture combined with Chinese herbal medicine: a systematic review and meta-analysis. Ann Palliat Med 2021;10(11):11430-11444. doi: 10.21037/apm-21-2565 knee osteoarthritis. Chinese Journal of Tissue Engineering Research 2021;25:2719-26.

42. Deng KF, Zhu Y, Wei XC, et al. Meta-analysis on clinical efficacy and safety of Thunder-Fire moxibustion in treating KOA. Journal of Clinical Acupuncture and Moxibustion 2020;36:44-50.

43. Li AA, Chen JY, Chen J, et al. Efficacy of arthroscopy combined with sodium hyaluronate for knee osteoarthritis: a meta-analysis. Chinese Journal of Tissue Engineering Research 2021;25:2437-44.

(English Language Editor: J. Chapnick) 